\section{SMART UPBRINGING, RE MUNICIPALITY NORWAY: A NEW MODEL FOR COMMUNITY HEALTH BASED ACTION RESEARCH}

Elisabeth S Paulsen. Leader of Services for Children and Family, Re Municipality, Norway

10.1136/injuryprev-2016-042156.278

Background In 2011 Re municipality was certified as Safe Community. Re is a small municipality in a rural area in Norway. Over the last 10 to 15 years the development in Re has been of some concern. An increasing number of children and youths struggle to manage their lives. A survey in junior high shows that $20 \%$ is depressed.Investment in early childhood can give great results and are well documented in several studies. Programs that take care of the populations physical health has been developed both internationally and in Norway. But when we searched for interdisciplinary programs that address psychological health and prevention during childhood there were none. This lead Re municipality to start a project in 2011, SMART upbringing. Our vision: Resilient children, youths and adults. SMART has become a model for our municipality to organise a continuously interdisciplinary prevention program that addresses children's mental health in all arenas and prevention levels. Our understanding is that if we affect the children's capacity to be resilient we can prevent mental illness, self harm, drug abuse and falling out of society.

Methods The SMART is inspired by several methods: Values through positive psychology, appreciative action research used to coordinate the efforts on booth micro level and organisational level across all services and social constructions to create a common terminology on strengths through storytelling that identify success in everyday life. Through repeating cycles using appreciative action research together with the children and their family, new knowledge develops. The tools are pictures, stories, films and posters created together with the children. The theoretical fundament is described in 3 books. The tools are used on all arenas in the municipality. Re has hired a sociologist to initiate a study over a period of 3 years to research and develop SMART upbringing.

Results SMART upbringing has become the largest interdisciplinary development project that addresses childhood and prevention of mental health. The culture is changing, and the focus is changing from repairing to preventing. From problems to strengths. Teachers, social and health workers reports that they gain better results in their work. SMART is a program that empower the children. We have achieved fewer children need special facilitated teaching from $11.5 \%$ to $7.3 \%$ (under the average in Norway). Fewer children reports on beeing bullied (under the average in Norway). The children services have received 37\% fewer reports on concern of neglect.

Conclusions It is our belief that SMART upbringing can contribute with knowledge on how a municipality can organise continuous interdisciplinary actions that safeguard and promote children's mental health in all services on all childhood arenas.

\section{9 TEAVIISARI - A TOOL FOR BENCHMARKING SAFETY PROMOTION AND INJURY PREVENTION ON LOCAL LEVEL}

Vesa Saaristo, Pia Hakamäki, Hanna Koskinen, Kirsi Wiss, Timo Ståhl. National Institute for Health and Welfare (THL), Finland

10.1136/injuryprev-2016-042156.279

Background In Finland, municipalities are responsible for promoting the health and welfare of their residents. Safety promotion and injury prevention are an integral part of health promotion on various fields of municipal action.

Description of the problem Until the launch of TEAviisari, a nationwide benchmarking tool for the management, planning and evaluation of health promotion capacity building (HPCB), there has been very little accurate and comparable nationwide information on health promoting activities in different sectors in Finnish municipalities.

Results Aiming to make measures taken by local authorities visible and to provide information on actions that promote better public health on local level, TEAviisari is based on a generic HPCB framework. The framework consists of seven dimensions: commitment, management, monitoring and needs assessment, resources, common practices, participation and core functions. Safety and injury related topics covered in TEAviisari include but are not limited to prevention of home and leisure accident injuries, inspection of health and safety at schools, home-school collaboration to promote safety, prevention and monitoring of accidents and injuries at school, compiling a local safety plan, evaluating older person's housing safety and having expertise on health and safety technology and assistive devices. The results show that differences between municipalities and schools exist in all topics. The data can be viewed on municipal level or on various geographical or administrative levels. Data for single schools are shown with the permission of the school.

Conclusions TEAviisari shows that it is possible to assess the HPCB of municipalities, serving as a tool for the local government while making it transparent to the residents. Web-based user interface provides a quick access to relevant, interpreted information for decision-makers. TEAviisari is free of charge and available at http://teaviisari.fi in Finnish, Swedish and English.

\section{KNOWLEDGE BROKERS: COMMUNITY PARTNERS IN YOUTH INJURY PREVENTION RESEARCH}

${ }^{1}$ Nicole Romanow, ${ }^{2}$ Megan McKinlay, ${ }^{3}$ Kyla White, ${ }^{4}$ Lisa Rosengarten, ${ }^{1,5}$ Brent Hagel,

${ }^{1,5}$ Carolyn Emery. ' Sport Injury Prevention Research Centre, University of Calgary, Canada; ${ }^{2}$ Ever Active Schools, Canada; ${ }^{3}$ WinSport Canada, Canada; ${ }^{4}$ Hockey Calgary, Canada; ${ }^{5}$ Cumming School of Medicine, University of Calgary, Canada

\subsection{6/injuryprev-2016-042156.280}

Background (issue/problem) Building strong partnerships between researchers and the community in youth sport and recreational injury prevention to promote active living and prevent chronic disease is a timely priority. Engaging community partners throughout the research process, from planning to dissemination, is critical to ensure project success, effective knowledge translation $(\mathrm{KT})$ and impact. 
Description of the problem Involvement of community stakeholders in research often includes pre-grant solicitation of support or end-phase KT activities. To facilitate optimal and timely input from key stakeholders at all stages of research, the Alberta Program in Youth Sport and Recreational Injury Prevention developed a Knowledge Broker (KB) model.

Results (effects/changes) In alignment with research priorities, KBs were identified in relevant community partner organisations (Ever Active Schools, Hockey Calgary, WinSport). KBs bridge the gap between research, education and KT priorities within the academic institution and the community. KB activities include contributing to research questions, intervention development, subject recruitment, implementation and dissemination of findings. Linking researchers and knowledge users facilitates collaboration, a greater understanding of common and diverse goals, and new partnerships. The ideal outcome of these partnerships includes optimal knowledge exchange to maximise the uptake of research evidence for the greatest public health impact. A financial contribution from the research program helps support the commitment of KBs.

Conclusions The integrated nature of the research program with academic and community stakeholder partnerships, creates an ideal setting for enhancing the impact of $\mathrm{KT}$. KB involvement contributes significantly to achieving research objectives. KB contributions optimise the translation of research findings into injury prevention practice, programs and policies.

\section{SAFE COMMUNITY IN MALAYSIA: A WISH AND A DREAM}

${ }^{1,2} \underline{R}$ Annapoornam, ${ }^{3}$ S Kulanthayan. ' SJK Tamil Kajang Parents Volunteer Group; ${ }^{2}$ Universiti Putra Malaysia; ${ }^{3}$ Safe Kids Malaysia

10.1136/injuryprev-2016-042156.281

Background Safe Community has benefited many countries which adopted it for many years. Malaysia has been exploring this initiative since year 2012 under the Ministry of Housing and Local Government then. Universiti Putra Malaysia (UPM) is championing this initiative with a high hope to have a serious buying in from any interested community.

Methods The approach undertaken by UPM is by identifying possible community. We took both (top-down and also bottomup approach) approach in our attempt to win the hearts of the stakeholders. For the 'top-down' approach, we presented to two government authorities - Ministry of Housing and Local Government and the next one Putrajaya Corporation the Safe Community Concept. For the 'bottom-up' approach, we are working closely with a community in Kajang, Selangor.

Results The initial feedback are positive from this two local authorities for the 'top-down approach'. However we have not moved much and far as we detailed down the operational part. The 'bottom-up' approach also is giving us the initial positive sign as we erode into a segment of the community (school children, teachers, parents and organisation that supports children betterment). For the 'bottom-up' approach with the Kajang Community, UPM has embarked and facilitated few safety programs namely: 1) Medical Camps and Health Screening including Dental Services and Pharmacy, 2) Weekly Swim Safety Classes for Children, Parents and Teachers, 3) Pedestrian Safety Intervention for the entire community, 3) Eye Project to Improve Children Vision, 4) Fire and Electrical Safety Demonstration for a segment of the community, 5) Importance of Food Safety and Healthy Food for School Community, 6) Lab Safety for the community who deals with lab and finally 7) Crime Prevention talks and session with the Kajang Police Station Officials.

Conclusions In Safety 2016 Conference, we would be able to share more information on bringing in Safe Community to Malaysia and it is our wish to announce that we have the first community who is interested and applied to join the Safe Community movement.

\section{Child Maltreatment}

\section{Parallel Tue 2.2}

\section{CHILD PROTECTION AND DISABILITY IN SCOTLAND: A CAUSE FOR CONCERN}

${ }^{1}$ Julie Taylor, ${ }^{2}$ Christine Jones. ${ }^{1}$ University of Birmingham, UK; ${ }^{2}$ University of Strathclyde, UK

\subsection{6/injuryprev-2016-042156.282}

Background Disabled children are at least four times more likely to be abused than their non-disabled peers. This abuse is likely to be of longer duration and be more severe. Despite this heightened risk, the abuse of disabled children often goes undetected and underreported. This qualitative study investigated the specific issues faced by practitioners in Scotland in supporting disabled children at risk of significant harm.

Methods The aim of this study, commissioned by the Scottish Government, was to assess how public services (including social work, health care, education, police and other related services) identify and support disabled children at risk of significant harm, whether neglect or abuse.

This study focused on children and young people with a wide range of impairments, including physical, sensory, cognitive and communication impairments and those with mental distress, all of whom are disabled by external barriers. The study involved four concurrent components: telephone interviews, focus groups with Child Protection Committees (CPCs), practice case studies and the development of systems and response models. Interviews were held with participants from six local authority areas and across five different services. We also held five focus groups with Child Protection Committees (61 participants in total). Inductive analysis following framework design was undertaken.

Results There were positive messages about putting the child at the very heart of child protection assessment and intervention, regardless of any impairment a child may have. However, there was also concern that practice was at times parent-centred. Some participants appeared to be 'muddling through' in practice and many practitioners lacked confidence when working with disabled children. Data from this study suggests that thresholds for disabled children may be higher than for non-disabled children. Participants reported high levels of interagency working and saw this as inherently positive, although they recognised some failings and tensions.

Conclusions There is widespread commitment across the child protection system to putting the child at the centre. However, getting it right for every child does not mean treating every child the same. 